ВАК 05.02.07

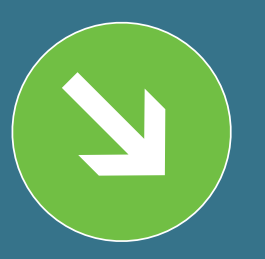

\title{
НОВЫЕ ТВЕРДЫЕ СПЛАВЫ И ИНСТРУМЕНТ «СКИФ-М» ДЛЯ ФРЕЗЕРОВАНИЯ
}

\section{Александр МоСквитИн}

В современном машиностроении применяется широкий спектр конструкционных материалов, объединенных по обрабатываемости согласно ИСО 513 в шесть групп: P, M, K, S, N и Н. Для обработки резанием этих материалов на рынке твердосплавного инструмента каждым мировым производителем предлагается большое количество марок твердых сплавов, часто дублирующих друг друга, что усложняет процесс выбора оптимального решения.

Современные достижения в области материаловедения, порошковой металлургии и технологии производства твердосплавных пластин, включая вакуумно-компрессионное спекание, новые тонкопленочные покрытия, позволяют получать новые марки твердых сплавов, имеющих уникальные свойства, которые возможно использовать при эффективной обработке нескольких групп материалов.

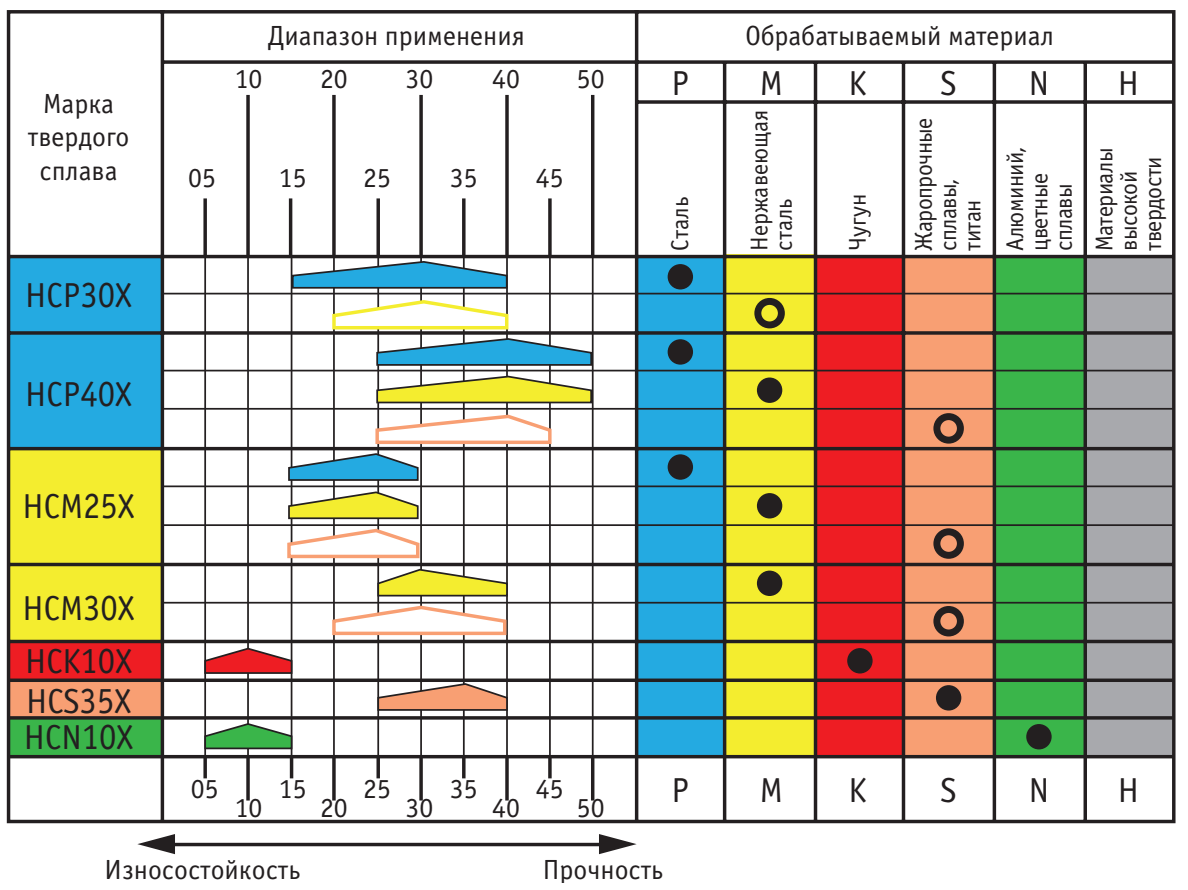

Puc. 1. Область применения новых твердых сплавов «СКИФ-М»
В результате комплекса работ, выполненных совместно с мировыми лидерами в области порошковой металлургии и PVD, а также с университетами России, «СКИФ-М» создал группу твердых сплавов, состоящую из семи марок, которая позволяет эффективно перекрыть практически весь диапазон обрабатываемых материалов, описываемый в ИСО 513 (рис. 1).

В последнее время все большее применение в режущем инструменте находит так называемая высокоположительная геометрия режущей части, характеризуемая значением переднего угла в нормальном сечении как в радиальном, так и осевом направлении более $10^{\circ}$, что справедливо и для сборных фрез с механическим креплением твердосплавных пластин. Такая геометрия обеспечивает минимальный расход энергии при механической обработке материалов и значительно уменьшает вероятность возникновения вибраций. Современная технология изготовления сменных твердосплавных пластин вместе с новыми субстратами предоставляет возможность получения экстремально малых углов заострения у пластин при одновременном сохранении их достаточной прочности, что и используется при создании «высокоположительных» фрезерных пластин нового поколения.

Компанией «СКИФ-М» на основе изложенного подхода создана широкая программа режущих пластин для фрезерования системы BD, отличающаяся экстремальным наклоном главной режущей кромки и большим значени- 


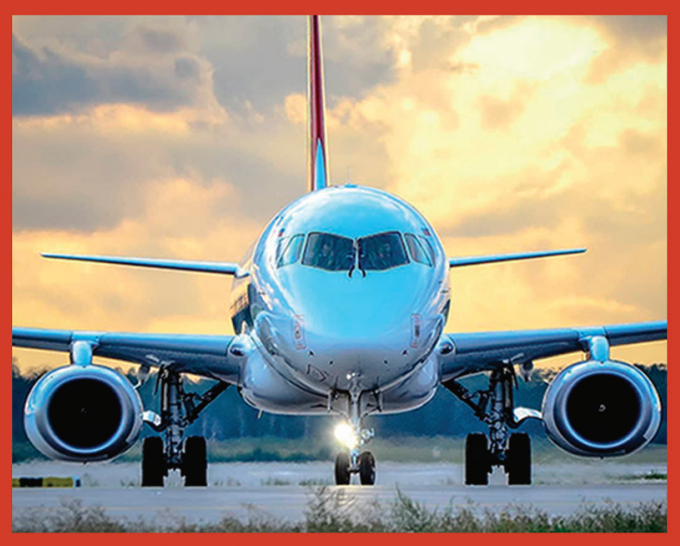

\section{Полная программа}

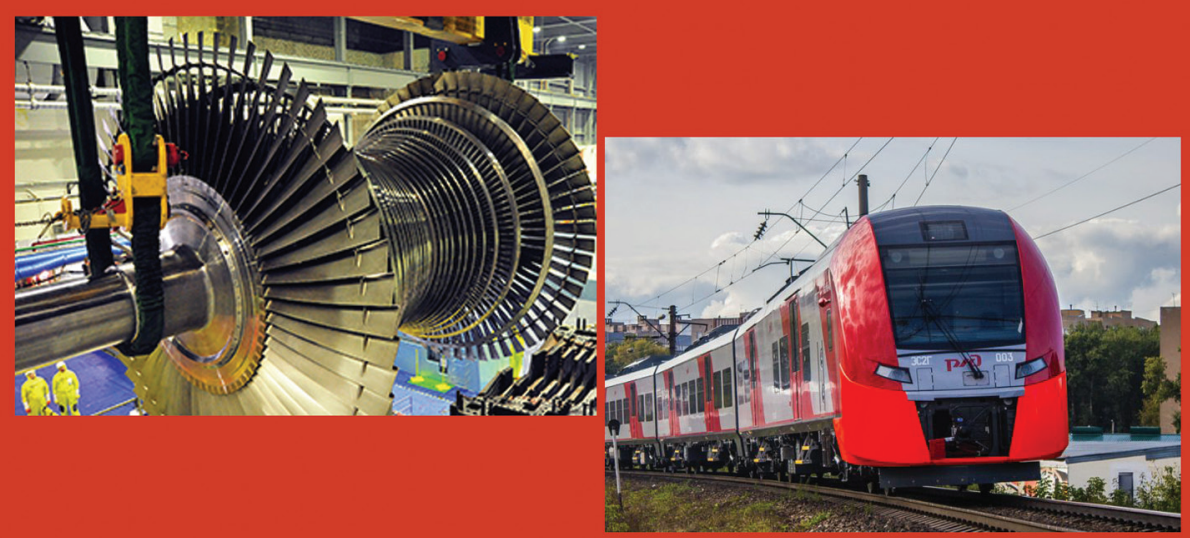

\section{тверАосплавного инструмента}

Аля фрезерования и сверления.

Металлообработка 2019 27-31 мая 2019 г.

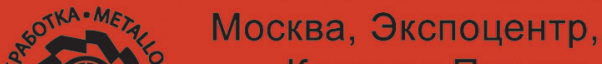
Красная Пресня, $\sum^{\frac{5}{4}}$

Пав.7.зал 6 Стенд 76 C48

СКИФ-М ООО

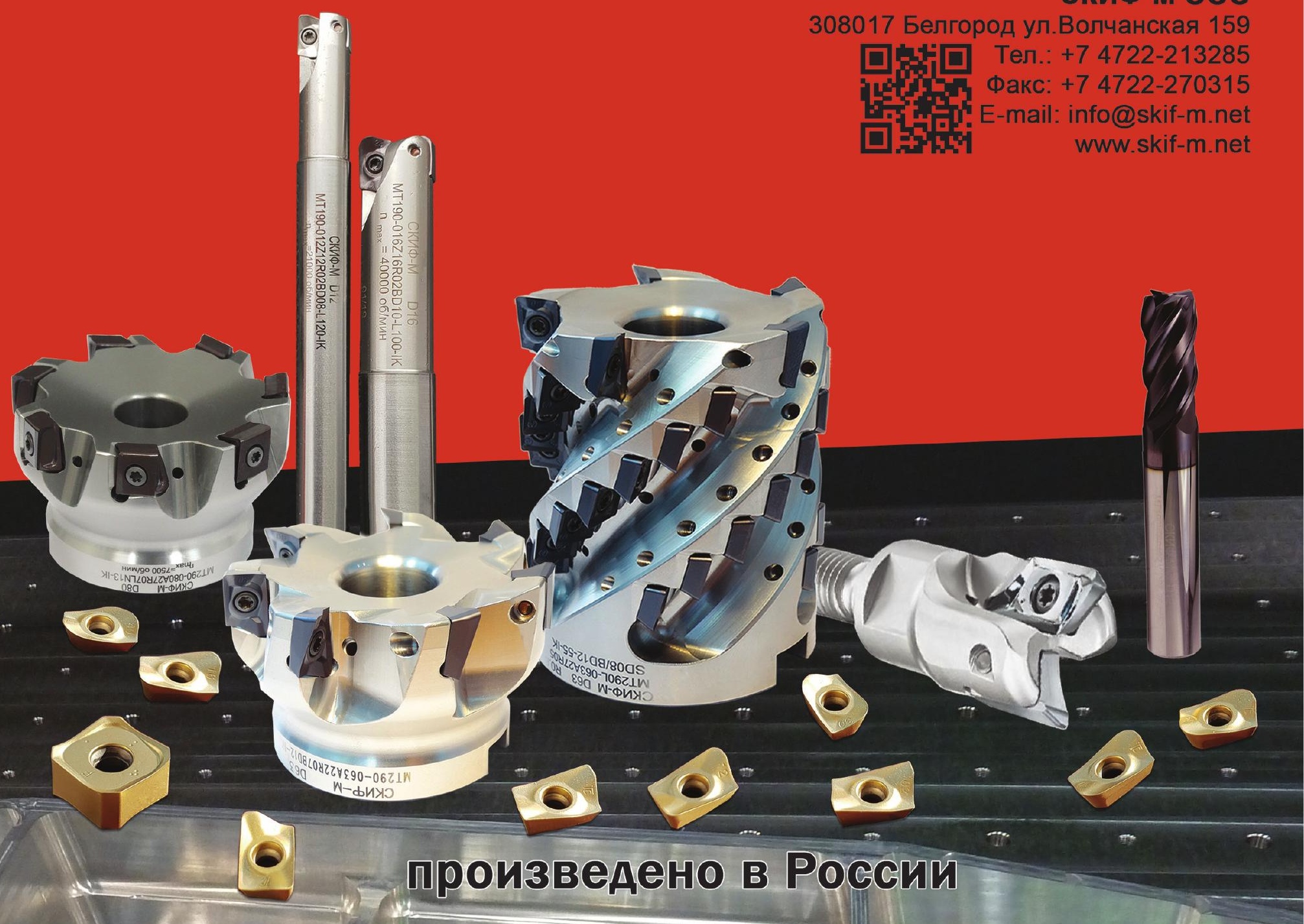




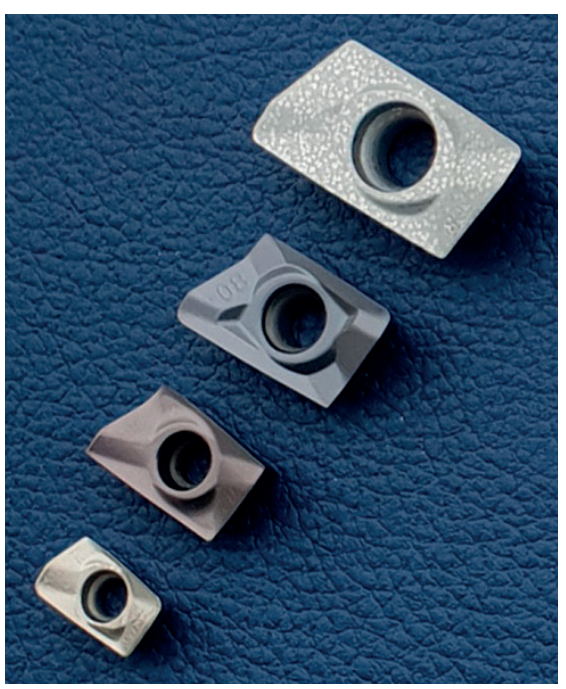

Puc. 2.

Программа пластин «СКИФ-М» системы BD состоит из четырех групп с длиной режущей кромки 8, 10,12 и 16 мм

ем переднего угла. Программа включает пластины $\mathrm{BD} 10$ с длиной режущей кромки 10 мм, пластины среднего размера BD12 с длиной режущей кромки 12 мм, самую маленькую пластину BD08 и самую большую - BD16 с длиной кромки 16 мм (рис. 2).

Пластины в каждой из групп могут выпускаться с различными значениями радиусов при вершине. Размеры радиусов при вершине большинства пластин, применяемых при механической обработке, стандартизованы и находятся в диапазоне от 0,2 до 5 мм.

Возможность установки в одном корпусе фрезы комплекта пластин с одним радиусом, с последующей заменой новым комплектом уже с другим необходимым радиусом из всего стандартного диапазона обеспечивает высокую гибкость технологического процесса механической обработки и снижение расходов на инструмент. Для этой цели «СКИФ-М» разработал и освоил на заводе в Белгороде производство сменных твердосплавных пластин типа BDMT10T3 универсального применения с длиной режущей кромки 10 мм со всеми стандартными радиусами. Новые сменные режущие пластины, кроме твердого сплава НСР40Х универсального применения, изготавливаются из специально созданного

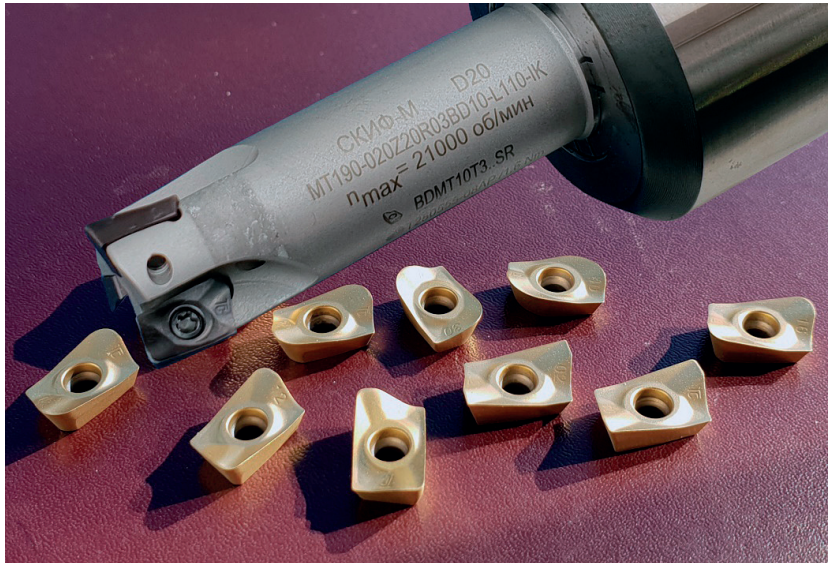

Puс. 3. Концевая фреза «СКИФ-М» диаметром 20 мм и сменные пластины с различными радиусами, устанавливаемые на эту фрезу

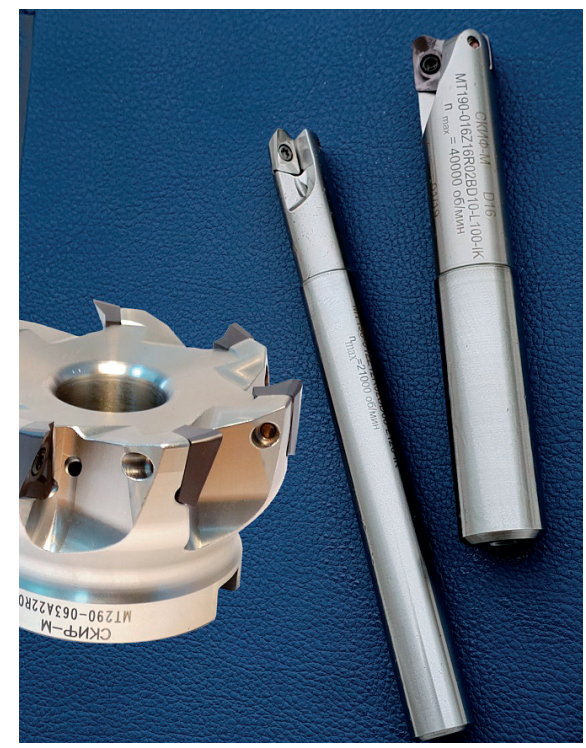

Puc. 4. Представители стандартного ряда торцовых и концевых фрез «СКИФ-М» для фрезерования пазов и уступов (в середине фреза диаметром 12 мм)

для титана сплава HCS35X. Для стали применяется сплав НСР30Х. Группа новых пластин включает девять типоразмеров стандартных радиусов: 0,2; 0,4; 0,$8 ; 1,2 ; 1,6 ; 2,0 ; 2,5 ; 3,0$ и 4,0 мм (табл. 1 , рис. 3 ).

С освоением выпуска самой маленькой пластины BD08 появилась возможность значительно расширить стандартный ряд концевых и торцовых фрез «СКИФ-М» и создать концевые фрезы со сменными пластинами диаметром 10 и 12 мм (рис. 4).

Применение этих фрез особо эффективно в авиационном двигателестроении и дает значительную экономию в сравнении с монолитным инструментом. 


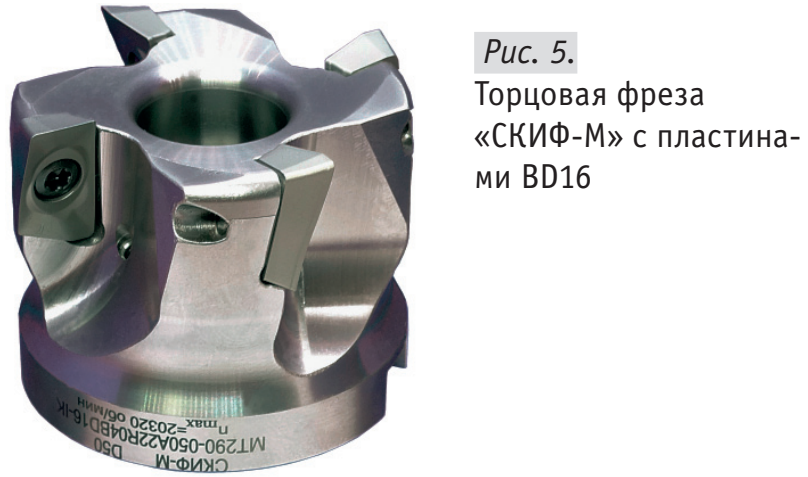

Фрезы с пластинами BD16 (рис. 5) предоставляют возможность обработки деталей с припуском до 15 мм за один проход.

Для высокоскоростной обработки алюминия кроме пластин с длиной режущей кромки 10 мм дополнительно создан ряд новых высокоточных пластин с длиной кромки 17 мм (рис. 6).

Конструкция этих пластин обеспечивает возможность высокопроизводительной обработки деталей самолетов со скоростью резания до 5000 м/мин. Твердый сплав для алюминия марки HCN10X отличается запатентованным в России

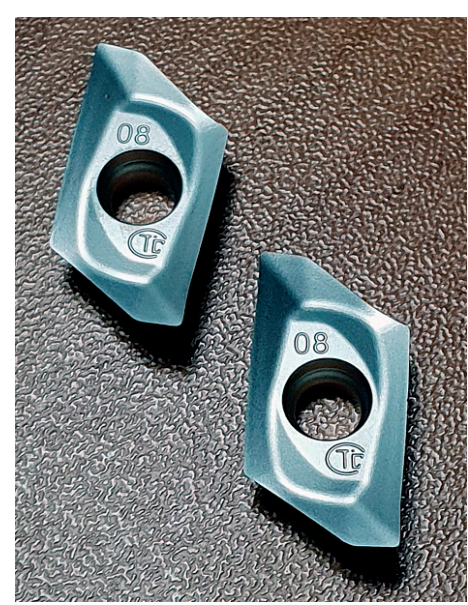

\section{Puc. 6.}

Новые режущие пластины «СКИФ-М» для высокоскоростного фрезерования алюминия сверхтвердым алмазоподобным покрытием, гарантирующим многократное увеличение стойкости инструмента.

\section{Москвитин Александр Александрович -}

кандидат технических наук,

генеральный директор

000 «СКИФ-М»

\section{НОВЫЕ КНИГИ ИЗДАТЕЛЬСТВА «ТЕХНОСФЕРА»}

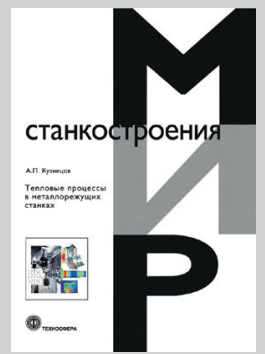

Цена 1090 руб.

\section{ТЕПЛОВЫЕ ПРОЦЕССЫ В МЕТАЛЛОРЕЖУЩИХ СТАНКАХ}

\section{Кузнецов А.П.}

В книге рассматриваются методы оценки теплового режима металлорежущих станков и их наиболее теплонапряженных деталей и узлов. Приведен механизм формирования и теплофизического анализа теплового режима деталей и узлов металлорежущих станков, дана их теплофизическая классификация и описываются типовые тепловые модели. Приводятся аналитические зависимости для оценки стационарного и нестационарного теплового режимов деталей и узлов станков.

Приведена классификация методов воздействия на тепловой режим станков, описаны способы снижения, коррекции, компенсации и управления тепловым режимом металлорежущих станков.

Предлагаемая монография может быть полезна студентам, аспирантам, а также инженерам и специалистам, занимающимся вопросами повышения точности при проектировании, производстве и эксплуатации металлорежущих станков. 